\title{
Spectrophotometric Estimation of Total Phenolic Content and Antioxidant Capacity of Molasses and Vinasses Generated from the Sugarcane Industry
}

\author{
Andrea Molina-Cortés ${ }^{1,2}\left(\mathbb{D} \cdot\right.$ Tatiana Sánchez-Motta $^{3} \cdot$ Fabian Tobar-Tosse $^{2,4}(\mathbb{D}) \cdot$ Mauricio Quimbaya $^{2,5}$ (D)
}

Received: 21 December 2018 / Accepted: 29 April 2019 / Published online: 6 May 2019

(c) The Author(s) 2019

\begin{abstract}
To identify a possible use for some agroindustrial wastes generated from the sugarcane industry, we evaluated the antioxidant capacity of $\mathrm{B}$ and $\mathrm{C}$ molasses and vinasses from the sugar and bioethanol production processes. Molasses and vinasses were characterized by physicochemical methods. Subsequently, the samples were diluted in distilled water at five concentrations to obtain aqueous extracts. Total phenolic content (TPC) of the samples was determined using a spectrophotometric method and was expressed in mg equivalents of gallic acid. The antioxidant capacity of each sample was determined by DPPH (2,2-diphenyl-1-picrylhydrazyl radical) and ABTS (2,2-azino-bis-[3-ethylbenzothiazoline-6-sulfonic acid]) methods, as well as the ferric-reducing power in FRAP (Ferric-reducing Antioxidant Power) assay. We found that, both for TPC and antioxidant capacity, the vinasses showed significantly higher values than the $\mathrm{B}$ and $\mathrm{C}$ molasses. These results showed a strong correlation between TPC and antioxidant capacity and revealed a remarkable increase in TPC and total antioxidant agents present in the extracts throughout the sugarcane transformation process. These findings allowed identifying vinasses as the by-product with the best antioxidant properties. Our work constitutes a first step in the study of molasses and vinasses as a promising antioxidant agent and as a novel resource to test in proliferative trials in cellular systems in vitro.
\end{abstract}

\section{Graphical Abstract}

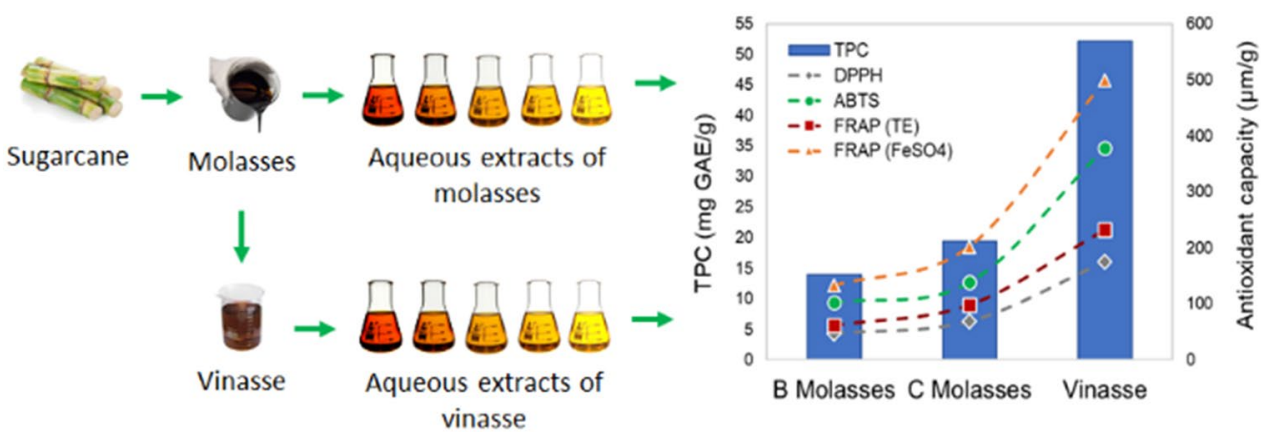

Keywords Saccharum officinarum $\cdot$ Phenolic compounds $\cdot$ Sugarcane by-products $\cdot$ Sugarcane distillery spent wash · Bioactivity $\cdot$ Added value

Andrea Molina-Cortés

amolina1@usbcali.edu.co

Extended author information available on the last page of the article

\section{Statement of Novelty}

In recent years, it has been shown that products with antioxidative activity might be used as potential agents to treat specific diseases like cancer. The possible application of either molasses or vinasses to further explore their potential 
as antioxidant elements or even as an antiproliferative agent in a cellular context opens a new perspective in which an agroindustrial waste is now transformed into a specific product with added value in the pharmaceutical industry. Our work is novel in the identification of vinasses as the byproduct with the best antioxidant properties, representing a new alternative for the use and recovery of this material, previously considered as industrial waste.

\section{Introduction}

Sugarcane agriculture supplies about $80 \%$ of the world sugar demand, being one of the most important crops worldwide [1]. In Colombia, there are 243.232 ha of sugarcane planted in the geographical valley of the Cauca River [2]. This crop contributes significantly to the national economy due to the industrialization of both sugar and bioethanol, which represents about $3.7 \%$ of the country's agricultural gross domestic product. In 2016, Colombia ranked 13th in the world ranking among 91 producing countries, which represented $1.3 \%$ of the world sugar production [2]. Complementarily, in 2017, the Colombian factories milled 24.38 million tons of sugarcane [2]. The current production implies the generation of considerable quantities of secondary and waste materials. From this perspective, novel alternatives might be found in order to promote the entire use of residues from the sugarcane industry. The generation of added value to these by-products is as important as the improvement and sustainability of the industry itself. On this basis, in recent years the sugarcane industry has expanded its research interests to the rational use of its by-products and wastes.

During the process of sugarcane industrialization, the stalks go through a series of mills that extracts the liquid fraction in which the sugars are diluted. From the evaporation of these juices and subsequent crystallization of the syrups, several types of molasses are generated, which differ in number and composition depending on the stages involved during the multiple-effect evaporation procedure. A tripleeffect evaporation process is generally applied, resulting in three types of molasses, namely A, B and C molasses [3, 4]. $\mathrm{A}$ and $\mathrm{B}$ molasses are recycled in order to maximize sucrose extraction; while C molasses (usually known as "molasses"), represents a side-product of sugar production that does not provide greater sucrose recovery. This final molasses has been considered as one of the most important by-products of the sugar industry, not only for its quantities between 3 and $7 \%$ of the weight of the harvested sugarcane [5-7] but also, due to its utility in animal feeding and it use as raw material for biofuel production [7-9].

As a consequence of the bioethanol production, either from sugarcane or from its by-products, vinasses are generated as waste effluents in proportions ranging from $3: 1$ to $15: 1$ (liters of vinasse per liter of bioethanol produced) $[5,10]$. These high volumes of production and features such as the high organic matter content and high chemical and biological oxygen demand (COD and BOD, respectively), turn the vinasses into a major environmental problem, since when they are dumped in water bodies such as rivers or lagoons, they produce several damages in the dynamics of these ecosystems [11, 12].

To give better use of this material, vinasses have been applied in low doses as agricultural fertilizer for soils [5, 13]. Although these practices contribute to the mitigation of the negative impacts associated with the generation of wastes during the sugar and ethanol processing, it is necessary to find other strategies for their complete use. An interesting alternative might be to explore the chemical and biological properties of molasses and vinasses, especially their potential antioxidant properties [8, 9, $14,15]$. Although in the current market several synthetic antioxidant compounds exist, a marked bias towards their natural sourcing is being generalized since natural compounds minimize the adverse effects attributed to the use of synthetic compounds. Complementarily, this promotes the more efficient use of biological raw materials, while simultaneously expands the need for generating new products with higher added value [16].

Although multiple studies have explored some of the products and by-products derived from sugarcane processing as a source of bioactive antioxidant compounds [4, 15, 17-23], the present study focuses on molasses and even more in vinasses since the latter are the less explored byproduct in the sugarcane industry in terms of its potential biological activity. Among the molecules that have been isolated from different matrices from sugarcane processing it is possible to find several compounds such as apigenin, luteolin, tricine, quercetin, and gallic, caffeic, chlorogenic, ferulic, vanillic, and syringic acids, among others $[4,15$, $17,18,21,24]$.

In a synergistic effect, the action of two substances together are greater than the sum of either effect alone, therefore the effects of a chemical mixture are extremely complex and may differ for each mixture depending on the chemical composition. This complexity is a major reason why mixtures have not been well studied. Nevertheless, there are increasing evidence of the synergistic effects of chemical mixtures over specific cellular responses and diseases outcomes. Although the antioxidant response of purified compounds from different extracts has been demonstrated, there is evidence suggesting an additive and synergic effect of the complex molecular mixture presents in a whole sample $[25,26]$. Accordingly, it is necessary to evaluate the overall antioxidant capacity of the generated by-products. In this respect, molasses and vinasses are interesting elements for evaluating their antioxidant capacity as whole matrices, 
even more, when as a future perspective the antiproliferative potential of molasses and vinasses in a cellular context will be assessed.

The present study aimed to determine the antioxidant capacity of molasses and vinasses derived from the processes of obtaining sugar and ethanol from sugarcane. This research represents an essential step for the definition of higher added value for these by-products and a contribution in the search for new sources of compounds with biological activities that would turn them into potential antioxidant agents for agroindustrial applications. Additionally, it has been shown that novel products with antioxidative activity might be used as potential agents to treat specific diseases as cancer $[27,28]$. The possible application of either molasses or vinasses to further explore their potential as antioxidant elements or even as an antiproliferative agents in in vitro assays, opens a new perspective regarding the potential therapeutic use of these by-products.

\section{Materials and Methods}

\section{Materials and Reagents}

Folin-Ciocalteu reagent, 2,2-diphenyl-1-picrylhydrazyl radical (DPPH), 2,2-azino-bis-[3-ethylbenzothiazoline-6-sulfonic acid] (ABTS), 2,4,6-tripyridyl-s-triazine (TPTZ), and the standards of gallic acid and Trolox were purchased from Sigma-Aldrich (St. Louis, MO, USA). All other chemicals and reagents used were of analytical grade.

The molasses and vinasses samples were supplied by the Colombian Sugarcane Research Center (Centro de Investigación de la Caña de Azúcar de Colombia-Cenicaña), which in turn receive them from the different sugar mills and distilleries of the country. Specifically, the molasses samples analyzed in this study came from Ingenio Riopaila-Castilla and the vinasses from Ingenio Providencia, both located in Valle del Cauca state, Colombia.

\section{Preparation of Samples}

C molasses samples were analyzed and compared with samples of an intermediate material (B molasses). The aqueous extracts of each sample were obtained by diluting separately $0.1,0.2,0.3,0.4$, and $0.5 \mathrm{~g}$ of molasses in $50 \mathrm{ml}$ of distilled water.

Vinasse samples were retrieved from the processing of sugarcane molasses to obtain ethanol. The aqueous extracts of vinasses were obtained diluting separately $0.3,0.4,0.5$, 0.6 , and $0.7 \mathrm{ml}$ of vinasse in $50 \mathrm{ml}$ of distilled water. Before undergoing the different analyses, both types of aqueous extracts (from molasses and vinasses) were homogenized and filtered through a filtering aid (Celite-Profinas S.A.S, Cali, Colombia).

\section{Physicochemical Characterization of By-Products}

The samples were characterized physiochemically regarding moisture content ( $\mathrm{MC} \%$ ), total soluble solids (TSS— ${ }^{\circ} \mathrm{Brix}$ ), and $\mathrm{pH}$. For these tests, the vinasse samples were analyzed directly, while $\mathrm{B}$ and $\mathrm{C}$ molasses were subjected to a previous dilution 1:5 $(\mathrm{w} / \mathrm{w})$ in order to facilitate data collection. The MC was determined by weight difference after vacuum drying for $24 \mathrm{~h}\left(65 \pm 2{ }^{\circ} \mathrm{C}, 13 \mathrm{kPa}\right)$ [29]. The TSS quantification was made by measuring the refractive index at $20{ }^{\circ} \mathrm{C}$ using a refractometer with electronic temperature control and conversion to Brix degrees values (Index Instruments Ltd. Model TCR 15-30). The $\mathrm{pH}$ readings were done directly on the vinasse samples and diluted molasses with a digital pH-meter (Hach ${ }^{\circledR}$ Model HQ11D). To complete the physicochemical characterization of the samples, the chemical and biological oxygen demands (COD and BOD, respectively) were determined.

\section{Quantification of Total Phenolic Content (TPC)}

Total phenolic compounds present in the aqueous extracts of $\mathrm{B}$ and $\mathrm{C}$ molasses and vinasses were quantified spectrophotometrically through the Folin-Ciocalteu test following the protocol of Singleton et al. [30] with specific modifications [31]. Gallic acid (GA) was used as standard and distilled water as the blank sample. In a $10 \mathrm{ml}$ volumetric flask, $4 \mathrm{ml}$ of distilled water were mixed with $0.4 \mathrm{ml}$ of the standard solution, the blank sample, or the extract to be analyzed. $0.4 \mathrm{ml}$ of Folin-Ciocalteu reagent was then immediately added and the solution was allowed to react for $5 \mathrm{~min}$. At the end of this period, $4 \mathrm{ml}$ of a $7 \% \mathrm{Na}_{2} \mathrm{CO}_{3}$ solution was added, the mixture was stirred, and the volumetric flask was brought up to volume with distilled water. After $90 \mathrm{~min}$ of incubation in the dark and at room temperature $\left( \pm 23{ }^{\circ} \mathrm{C}\right)$, the solution absorbance was measured at $730 \mathrm{~nm}$ using a spectrophotometer (Jenway ${ }^{\circledR}$ Model 7315 UV/Visible single beam). The TPC was expressed as mg equivalents of GA per $\mathrm{g}$ of dry matter (mg GAE/g).

\section{Determination of Antioxidant Capacity}

The antioxidant capacity was analyzed as the potential of the samples for free radical scavenging. According to this, DPPH, ABTS, and FRAP tests were applied.

\section{DPPH· Scavenging Activity}

To determine the scavenging activity of the DPPH radical (DPPH·) the procedure proposed by Brand-Williams et al. 
[32] was applied with specific modifications [8, 33], using Trolox as standard and methanol as the blank sample. In a test tube, $3 \mathrm{ml}$ of a $0.1 \mathrm{mM}$ DPPH - methanolic solution and $0.15 \mathrm{ml}$ of the standard solution, the blank sample, or the extract to be analyzed, were added. The mixture was stirred in a vortex for $10 \mathrm{~s}$ and allowed to react in the dark for $30 \mathrm{~min}$ at room temperature. After this time, the solution absorbance was measured at $517 \mathrm{~nm}$ in a spectrophotometer (Jenway ${ }^{\circledR}$ Model 7315 UV/Visible single beam). The antioxidant activity was expressed as the inhibition percentage according to the following equation:

$I[\%]=\frac{A_{0}-A}{A_{0}} \times 100$

where $A_{0}$ corresponds to the absorbance value of the blank sample, and $A$ is the absorbance value of the analyzed sample. From the Trolox calibration curve, the Trolox Equivalent Antioxidant Capacity (TEAC) was calculated and was expressed in micromoles of Trolox Equivalents (TE) per $g$ of dry matter $(\mu \mathrm{mol} \mathrm{TE} / \mathrm{g})$. Additionally, the results were expressed according to $\mathrm{IC}_{50}$ parameter, which refers to the concentration of sample required to achieve a $50 \%$ inhibition of the radical. $\mathrm{IC}_{50}$ was calculated from the function that relates the percentages of inhibition reached by the samples at different concentrations [8, 24].

\section{ABTS. ${ }^{+}$Scavenging Activity}

The scavenging activity of the ABTS cation radical $\left(\right.$ ABTS $^{+}$) was determined using the methodology developed by Re et al. [34] with specific modifications [15, 17]. As in the DPPH test, Trolox was used as a standard, but ethanol was used as the blank sample. In this test, ABTS. ${ }^{+}$must be previously generated through the reaction of a $2.45 \mathrm{mM}$ potassium persulfate solution and a $7 \mathrm{mM}$ ABTS solution in a 1:1 volumetric ratio. This mixture was allowed to react in the dark at room temperature for at least $16 \mathrm{~h}$ before use. The obtained radical was diluted in ethanol until reaching an absorbance of $0.7 \pm 0.02$ at $734 \mathrm{~nm}$. In a test tube, $3 \mathrm{ml}$ of the diluted ABTS. ${ }^{+}$and $40 \mu \mathrm{l}$ of the standard solution, the blank sample, or the extract to be analyzed, were added. This mixture was stirred in a vortex for $10 \mathrm{~s}$ and allowed to stand in the dark at room temperature. After 6 min, the solution absorbance was measured at $734 \mathrm{~nm}$ using a spectrophotometer (Jenway ${ }^{\circledR}$ Model 7315 UV/Visible single beam). In the same way as in the DPPH assay, the results of this test were expressed as TEAC $(\mu \mathrm{mol} \mathrm{TE} / \mathrm{g})$ and $\mathrm{IC}_{50}$.

\section{Ferric-Reducing Antioxidant Power (FRAP) Assay}

FRAP was evaluated according to the adaptations of the Benzie and Strain method $[35,36]$ suggested by Pulido et al.
[37] and other authors [14, 38]. Trolox and ferrous sulfate $\left(\mathrm{FeSO}_{4}\right)$ were used as standards, and distilled water was used as the blank sample. Before the application of each test, FRAP reagent should be prepared and maintained throughout the process in a water bath at $37^{\circ} \mathrm{C}$. FRAP reagent was obtained from the mixture in a 10:1:1 ratio (by volume) of a $300 \mathrm{mM}$ acetate buffer (pH 3.6), a $20 \mathrm{mM}$ ferric chloride solution, and a $10 \mathrm{mM}$ TPTZ solution prepared with a $40 \mathrm{mM} \mathrm{HCl}$ solution. In a test tube, $2.85 \mathrm{ml}$ of freshly prepared FRAP reagent was mixed with $150 \mu \mathrm{l}$ of the standard solution, the blank sample, or the extract to be analyzed. This mixture was stirred in a vortex for $10 \mathrm{~s}$ and was placed in the dark at room temperature. After 30 min of incubation, the solution absorbance was measured at $593 \mathrm{~nm}$ using a spectrophotometer (Jenway ${ }^{\circledR}$ Model 7315 UV/Visible single beam). The antioxidant capacity was expressed as FRAP Value in micromoles of Trolox and ferrous sulfate equivalents per g of dry matter $\left(\mu \mathrm{mol} \mathrm{TE} / \mathrm{g}\right.$ and $\mu \mathrm{mol} \mathrm{FeSO}_{4} / \mathrm{g}$, respectively).

\section{Statistical Analysis}

All data were expressed as the mean \pm the standard deviation. For the results analysis, a unifactorial analysis of variance (ANOVA) completely randomized, with a confidence level of 95\% was applied. For the identification of treatments with significant differences, Tuckey's means comparison test was applied. These analyzes were done with the software SPSS (PASW Statistics 18, version 18.0.0).

\section{Results and Discussion}

\section{Physicochemical Characterization of Molasses and Vinasses}

The MC, TSS, pH, COD, and BOD values of the analyzed samples are presented in Table 1. The TSS exhibited by $\mathrm{B}$ and $\mathrm{C}$ molasses are into the established ranges by the Colombian Technical Standard NTC 587/1994 for this kind of by-products [39]. Likewise, the TSS and pH values of $\mathrm{C}$ molasses are very similar to those obtained by Gasmalla et al. [40]. As for the vinasse, although TSS are slightly higher than the reported by Aristizábal [41] and Ahmed et al. [12], these parameters as well as the $\mathrm{pH}, \mathrm{COD}$, and BOD are typical of this kind of materials and are within the ranges reported by various authors [11-13].

After harvesting and entering the factory for processing, the sugarcane stalks go through a series of transformations that give rise to sucrose and ethanol as primary products. One of the intermediate products from which the sugar crystals are extracted corresponds to B molasses, which comes from the evaporation of sugarcane juices and subsequent 
Table 1 Physicochemical characterization of analyzed molasses and vinasses

\begin{tabular}{llllrr}
\hline Sample & MC $(\%)$ & TSS $\left({ }^{\circ}\right.$ Brix $)$ & pH & COD $(\mathrm{g} / \mathrm{l})$ & BOD $(\mathrm{g} / \mathrm{l})$ \\
\hline B Molasses & $27.40 \pm 9.52^{\mathrm{a}}$ & $80.08 \pm 0.67^{\mathrm{a}}$ & $6.10 \pm 0.02^{\mathrm{a}}$ & 1786.74 & 6388.99 \\
C Molasses & $22.58 \pm 6.66^{\mathrm{a}}$ & $84.09 \pm 0.53^{\mathrm{b}}$ & $5.91 \pm 0.01^{\mathrm{b}}$ & 830.32 & 389.44 \\
Vinasse & $90.31 \pm 1.12^{\mathrm{b}}$ & $14.92 \pm 0.03^{\mathrm{c}}$ & $4.91 \pm 0.01^{\mathrm{c}}$ & 70.81 & 35.58 \\
\hline
\end{tabular}

Values with different superscript letters in the same columns are significantly different $(\mathrm{p}<0.05$; one-way ANOVA followed by Tukey's test)

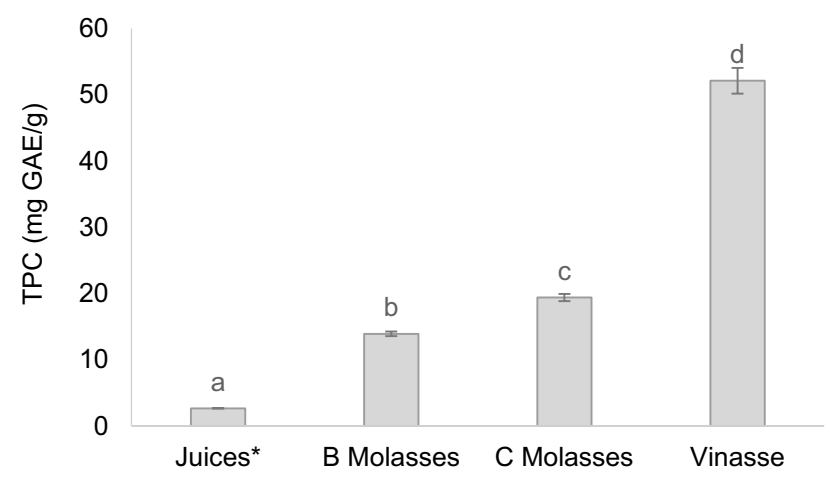

Fig. 1 TPC of B and C molasses and vinasses samples. Bars with different letters are significantly different $(p<0.05$; one-way ANOVA followed by Tukey's test). *The results for sugarcane juices are shown in the graph as a reference point

crystallization of syrups. In this sense, it is expected to obtain molasses with low moisture and high concentration of TSS. However, B molasses is an intermediate material from which some sucrose crystals can still be extracted. From the processing of B molasses, an exhausted syrup is generated that is much more concentrated but does not offer a higher sucrose recovery. This by-product, known as $\mathrm{C}$ molasses, tends to present higher ${ }^{\circ} \mathrm{Brix}$ values and lower moisture values than B molasses (Table 1). As a consequence of TSS concentration in molasses, a progressive reduction of the $\mathrm{pH}$ occurs due to different organic compounds naturally present in the sugarcane juices, and others formed during the manufacturing process, including several organic acids such as formic, acetic, and lactic acids [42]. On the other hand, vinasse constitutes a liquid waste generated during the bioethanol production from sugarcane or its by-products. Its high concentration of micronutrients and organic compounds (reflected in the high COD and BOD valuesTable 1) produce remarkable acidification of the medium $[12,13]$, which confirms the polluting potential of sugarcane by-products and highlight the necessity for finding different strategies for their use.

\section{Total Phenolic Content (TPC) of Molasses and Vinasses}

Figure 1 represents the TPC of the different analyzed samples. We found a marked difference in TPC values among vinasses and $B$ and $C$ molasses $(p<0.05)$, since the former presented a TPC of $52.10 \pm 1.93 \mathrm{mg} \mathrm{GAE} / \mathrm{g}$, while B and C molasses had values of $13.91 \pm 0.36$ and $19.40 \pm 0.54 \mathrm{mg}$ $\mathrm{GAE} / \mathrm{g}$, respectively. Considering that sugarcane juices have a TPC of $2.67 \pm 0.04 \mathrm{mg} \mathrm{GAE} / \mathrm{g}$, these results reveal an apparent increase of phenolic compounds in the intermediate products and by-products as the sugarcane transformation process progresses. It has been reported that the increase of phenolic compounds in the downstream processing by-products would be related to the release of the aglycones from the phenolic glycosides present in sugarcane juices, which would cause a higher concentration of this free phenolic structures in molasses and vinasses [43, 44]. In this respect, Duarte-Almeida et al. [18] and Payet et al. [4] have argued that some of the phenolic compounds found in molasses could be obtained as a product of the degradation of hydroxycinnamic acid derivatives present in sugarcane juices. This phenomenon occurs during milling processes, where certain enzymatic reactions are induced to promoting the methylation of caffeic acid to produce ferulic acid. Furthermore, it has been pointed out that both ferulic acid and vanillin can be obtained from lignin and hemicellulose and hydrolyzed during the extraction of sugarcane juices [4].

Usually, sugarcane juices have a turbid appearance and a marked coloration in different green-brown tones. As it has been known, these characteristics derive from the presence of various organic compounds, including phenolic compounds $[45,46]$. Industrially, the coloration of the sugarcane juices has been an undesirable attribute due to its influence on the final quality of white sugar crystals obtained from them. That is why it is necessary to apply clarification processes. However, when the colored compounds are removed from the sugar crystals, a part of them (including phenolic compounds) are retained in the different secondary streams, being found in significant quantities in $\mathrm{B}$ and $\mathrm{C}$ molasses [4]. Regarding the vinasse, this type of compounds also remains in significant quantities in this waste, since yeasts do not consume them during the sugar fermentation, and neither are degraded during the distillation processes [22]. 
When we compare our TPC values found for sugarcane molasses and vinasses with other plant products we can observe these by-products are below of high antioxidant power products such as blackberries and blueberries, which are highly colored and have revealed phenolic contents between 67.1 and $126.3 \mathrm{mg} \mathrm{GAE} / \mathrm{g}$ [47]. However, other products of recognized antioxidant value such as basil, spinach, and apples have TPC values relatively close to those found in the analyzed vinasses samples (between 51.4 and $53.5 \mathrm{mg} \mathrm{GAE} / \mathrm{g}$ ) [47, 48]. Meanwhile, other plant products such as carrots, cucumbers, cabbages, and parsley are in ranges close to the values found in $\mathrm{C}$ molasses (between 18.8 and $21.0 \mathrm{mg} \mathrm{GAE} / \mathrm{g}$ approximately) $[47,48]$.

An important limitation recognized by the scientific community arises when comparing the results of different studies on the characterization of phenolic compounds and antioxidant capacity, due to factors such as the origin of raw materials, previous treatments applied to samples, and methodological variations of the protocols. Although our findings show values of TPC that differ from those obtained by other authors for sugarcane molasses, they do exhibit similar behavior as the one published in the literature $[4,49]$. This fact could be explained by considering the heterogeneity of the analyzed samples and the presence of different molecules that could interfere in the analytical determinations.

\section{Antioxidant Capacity of Molasses and Vinasses}

Generally, antioxidant compounds act by different mechanisms depending on the reaction conditions, for example, according to the type of molecule and the oxidizing agents on which they react [50]. Based on the chemical reactions involved, the antioxidant capacity in vitro can be determined by methods that are based on hydrogen atom transfer (HAT) or single electron transfer (SET) reactions [51]. Up to date, no single method accurately determines the antioxidant capacity of a complex system; for this reason, it is necessary to apply several procedures to the samples to have a better approximation on the antioxidant capacity [50-52]. With this respect, DPPH and ABTS assays have been widely used to evaluate the antiradical activity of a sample based on its ability to transfer electrons or hydrogen atoms. Similarly, the FRAP assay measures this property based on the ability of the antioxidant compounds to transfer electrons and, consequently, to reduce ferric iron (III) to ferrous iron (II) $[50,52]$.

As highlighted in Fig. 2, in all assays performed in this study, we found a positive correlation between the concentration of the samples and their antioxidant capacity $\left(0.9913<\mathrm{R}^{2}<0.9998\right)$. From DPPH and ABTS tests, as well as in the FRAP assay, it was found that vinasse has better antioxidant properties than $\mathrm{B}$ and $\mathrm{C}$ molasses since it presented significantly higher values of TEAC and FRAP
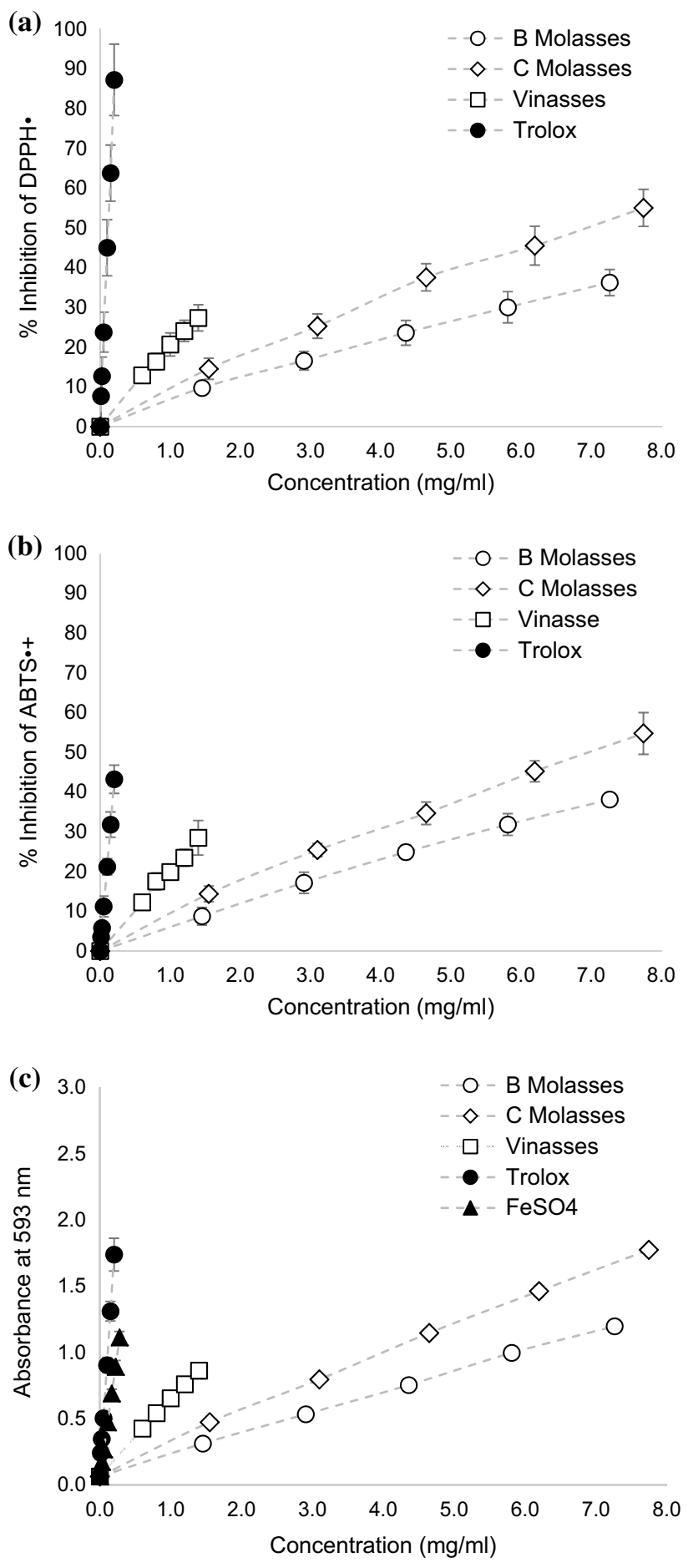

Fig. 2 Relation between concentration of samples and their antioxidant response: a Percentages of inhibition of DPPH $\cdot, \mathbf{b}$ Percentages of inhibition of ABTS ${ }^{+}$, and c Absorbance at $593 \mathrm{~nm}$ determined by the FRAP method

$(\mathrm{p}<0.05)$, as well, as significantly lower $\mathrm{IC}_{50}(\mathrm{p}<0.05)$ (Table 2). This last parameter is inversely proportional to the antioxidant capacity; hence the amount of vinasse required 
Table 2 Antioxidant capacity of B and C molasses and vinasses samples analyzed under three free-radical scavenging assays in vitro

\begin{tabular}{|c|c|c|c|c|c|c|}
\hline \multirow[t]{2}{*}{ Samples } & \multicolumn{2}{|l|}{ DPPH } & \multicolumn{2}{|l|}{ ABTS } & \multicolumn{2}{|l|}{ FRAP } \\
\hline & TEAC ( $\mu \mathrm{mol} \mathrm{TE} / \mathrm{g})$ & $\mathrm{IC}_{50}(\mathrm{mg} / \mathrm{ml})$ & TEAC ( $\mu \mathrm{mol} \mathrm{TE} / \mathrm{g})$ & $\mathrm{IC}_{50}(\mathrm{mg} / \mathrm{ml})$ & FRAP Value $(\mu \mathrm{mol} \mathrm{TE} / \mathrm{g})$ & FRAP Value $\left(\mu \mathrm{mol} \mathrm{FeSO}_{4} / \mathrm{g}\right)$ \\
\hline B Molasses & $46.41 \pm 6.47^{\mathrm{a}}$ & $9.88 \pm 0.20^{\mathrm{a}}$ & $102.34 \pm 11.40^{\mathrm{a}}$ & $9.31 \pm 0.48^{\mathrm{a}}$ & $61.29 \pm 10.25^{\mathrm{a}}$ & $132.35 \pm 10.46^{\mathrm{a}}$ \\
\hline C Molasses & $68.45 \pm 8.12^{\mathrm{b}}$ & $6.77 \pm 0.57^{\mathrm{b}}$ & $138.16 \pm 9.93^{\mathrm{b}}$ & $6.89 \pm 0.46^{\mathrm{b}}$ & $97.85 \pm 5.73^{b}$ & $202.12 \pm 2.99^{\mathrm{b}}$ \\
\hline Vinasse & $175.65 \pm 23.99^{c}$ & $2.52 \pm 0.30^{\mathrm{c}}$ & $377.71 \pm 39.09^{c}$ & $2.49 \pm 0.29^{c}$ & $232.05 \pm 14.59^{\mathrm{c}}$ & $498.72 \pm 11.54^{\mathrm{c}}$ \\
\hline Trolox & - & $0.11 \pm 0.01^{\mathrm{d}}$ & - & $0.23 \pm 0.02^{\mathrm{d}}$ & - & $7876.99 \pm 646.89^{\mathrm{d}}$ \\
\hline
\end{tabular}

Values with different superscript letters in the same columns are significantly different $(\mathrm{p}<0.05$; one-way ANOVA followed by Tukey's test)

to achieve the $50 \%$ of free radical scavenging is lower compared to both $\mathrm{B}$ and $\mathrm{C}$ molasses.

Based on the results presented in Table 2 it is possible to observe that, in all cases, the antioxidant capacity in TE is higher in the ABTS method. This behavior is similar to the observed by many researchers who have noticed a better inhibitory activity against ABTS ${ }^{+}$than DPPH $\cdot$ [53]. As it has been reported, this differential response would be related to the steric accessibility of the antioxidant molecules to the bulk radicals $[54,55]$. For the ABTS method, antioxidant compounds that function primarily via SET or do not have bulky ring systems have better access to the radical site, so they react rapidly. Meanwhile, antioxidant with more complex structures or functioning via HAT also react, although in a slower way [54]. These effects produce faster reaction kinetics, and higher antioxidant responses [53]. In contrast, DPPH method is more selective in HAT reactions since radical does not react with aromatic acids containing only one OH-group [55]. On the other hand, it has been noticed that compounds that show activity in the ABTS assays will also react in the FRAP assays, that is because of the similarity in its redox potentials. However, since the FRAP assay must be performed at an acidic $\mathrm{pH}$ to protect iron solubility (which increases the redox potential), FRAP values are usually lower than ABTS assay values [54].

Previously, the potential presented by several products and by-products derived from the sugarcane industry as a source of antioxidant molecules has been reported [4, 15, $17,45,56]$. Among the by-products generated in the factory, it has been more widespread established the analysis of $\mathrm{C}$ molasses compared to vinasses. In fact, regarding vinasses, just one study is known for addressing its potential as a source of antioxidant compounds [22]. Despite the marked interest that has been raised towards $\mathrm{C}$ molasses, the presented data in Table 2 show how the antioxidant capacity of vinasse, represented by $\mathrm{IC}_{50}$, TEAC, and FRAP values, exceeds approximately 2.6 times at $\mathrm{C}$ molasses and 3.7 times $\mathrm{B}$ molasses. When comparing these values between both molasses, the difference, although statistically significant ( $p<0.05$ ), is not important. In contrast, when comparing the antiradical capacity of the samples with the data obtained from a recognized antioxidant as Trolox, the vinasse samples

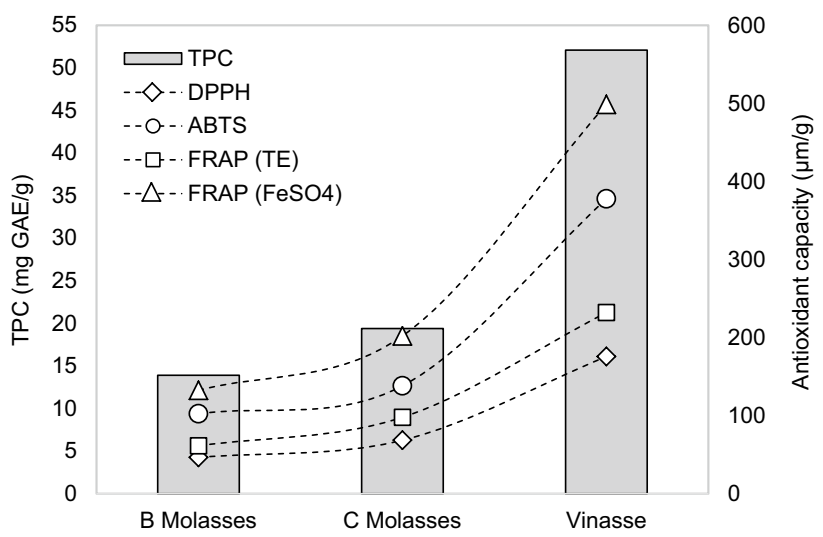

Fig. 3 TPC and antioxidant capacity of B and C molasses and vinasse samples

did not exceeded their reducing power in none of the performed tests. Accordingly, it is possible to consider these results as a quality indicator for vinasse valorization, since from such a complex mixture, new alternatives could be explored for their use as antioxidant agents of valuable industrial interest. For example, it has been suggested that antioxidative properties might be related with other biological activities such as inhibition of cell proliferation [27, 28]. This could be exploited at a pharmacological level to deepen into the study and treatment of specific diseases such as cancer.

\section{Correlation Between TPC and Antioxidant Capacity}

According to our findings, the relation of the antioxidant capacity between B molasses and vinasses is 1:3.7, which is consistent with the relation shown by TPC between these two by-products. For the case of $\mathrm{C}$ molasses and vinasses, the relation of antioxidant capacity is $1: 2.6$, which remains similar with the spectrophotometric quantification of phenolic compounds (Fig. 3). Several researchers have demonstrated the antioxidant properties exerted by phenolic compounds, especially those associated with their ability to scavenge free radicals [57-60]. Naturally, phenolic compounds came from the secondary plant metabolism, playing 


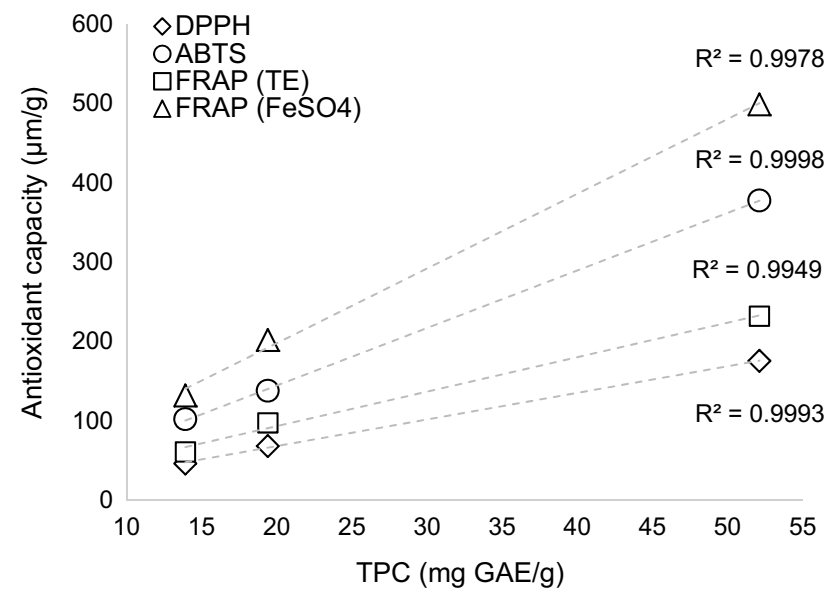

Fig. 4 Correlation between TPC and antioxidant capacity determined by DPPH, ABTS, and FRAP methods

various non-nutritional roles related to different adaptation mechanisms to the environment, for example, as a defense system against physicochemical and biological effects such as ultraviolet radiation, oxidizing agents, pathogenic microorganisms, parasites, predators, and diseases [61]. When this natural function of phenolic compounds in plants is considered, it is to be expected that these compounds might exhibit some biological activity in vitro. Additionally, when considering its molecular structure, factors such as the abundant presence of conjugated double bonds, and the multiple hydroxyl groups, provide to phenolic compounds the optimal chemical characteristics to prevent and combat oxidative damage caused by free radicals [57-62].

As a result of the study of aqueous extracts of $\mathrm{B}$ and $\mathrm{C}$ molasses, and vinasses, we confirmed the strong correlation between its TPC and its ability to scavenge free-radicals (Fig. 4). This behavior has been widely demonstrated by several authors, who have established a collectively accepted fact that the antioxidant properties of different biological matrices are derived from the presence of phenolic compounds $[57,58,63,64]$. However, even though the Folin-Ciocalteu test has traditionally been associated with TPC determination, it is known that other types of reducing molecules intervene in the reaction, leading to overestimation errors. Accordingly, the Folin-Ciocalteu test, beyond quantifying phenolic compounds, considers the totality of antioxidant agents present in a sample [4, 17, 54].

Previous studies have indicated that phenolic compounds from the plant secondary metabolism are not solely responsible for the characteristic colors of sugarcane juices and its derivative products $[45,46]$. Other molecules formed from the harvest and during the transformation processes within the factory exist, for example, some compounds originated from changes in temperature, $\mathrm{pH}$, or by the interaction among different components of the material. These compounds, known as Maillard reaction products (MRPs), arise from the reaction between the free amino groups and the carbonyl groups present in the sugarcane products, with the intermediation of high temperatures involved throughout the production process $[17,61,65]$. As with phenolic compounds, MRPs are eliminated from the white sugar crystals and retained in colored products and by-products such as $\mathrm{B}$ and $\mathrm{C}$ molasses and vinasses, giving them their particular flavors, aromas, and brown colors [46]. As reported previously, MRPs have revealed antiradical activities that add specific effects exerted by phenolic compounds to the antioxidant [22, 65-69]. It is necessary to carry out more in-depth studies that allow the identification of the different types of compounds present in the analyzed samples, and that may exhibit antioxidant activity in vitro.

The present study is the first one exploring the antioxidant potential of sugarcane molasses and vinasses. Nevertheless, it is of our interest to explore the antiproliferative potential of both by-products, in a biological context. From this perspective, most studies about the effects of chemicals on biologic systems are conducted on one compound at a time. However, at cellular level, they are exposed to mixtures, not single chemicals. Although various substances may have totally independent actions, in many cases two or more elements may act at the same receptor, the same transductional cascade, or over the same biochemical pathway, in ways that can be additive. There are increasing evidence of the synergistic effects of chemical mixtures over specific cellular responses. Carpenter et al. [70] clearly exemplify the additive effects of chemical mixtures that are used in the treatment of specific human diseases as cancer or neurodegenerative problems. Given that as a future perspective we want to evaluate the antiproliferative potential of sugarcane molasses and vinasses in a cellular context, it is worth to take into account for the in vitro cellular assays the analyzed matrices as a whole rather than as separated chemicals, in such a way the synergistic effects that the different substances present in the mixture might have over the cellular response would be dismissed. Accordingly, the possible application of either molasses or vinasses to further explore their potential as antioxidant elements or even as an antiproliferative agents in in vitro assays, opens a new perspective regarding the potential therapeutic use of these by-products.

\section{Conclusions}

In vitro tests here applied to determine the free radicals scavenging capacity of aqueous extracts of B and C molasses and vinasses generated during the sugar and ethanol processing, allowed to identify vinasse as the by-product with better antioxidant properties; this associated with its higher concentration of total phenolic compounds. Based on 
the analysis carried out, the relationship between these two variables (antioxidant capacity and TPC) was confirmed. Likewise, it was observed how the products and by-products derived from a higher degree of processing of sugarcane juices increase their ability to neutralize free radicals. This fact could indicate that the transformation processes applied to sugarcane enhance the concentration of bioactive molecules naturally present in the stalks, and also promote the formation of other organic compounds such as MRPs or phenolic compounds that contribute to the antioxidant response observed in vitro. In this sense, most of these antioxidant compounds are retained in the different secondary streams such as $\mathrm{C}$ molasses and vinasse.

As a result of the evaluation of the antioxidant behavior of the aqueous extracts from sugarcane molasses and vinasses, the way has been opened to extend our research towards the exploration of the antiproliferative potential of both byproducts, in a biological context. Our findings suggest, in general, a real potential of sugarcane molasses and vinasses as a source of bioactive compounds with antioxidant capacity. These results could promote the entire use of a natural resource of high commercial interest such as sugarcane. Furthermore, finding biologically active molecules in this kind of by-products point towards the idea that such by-products could be applied, in the future, as active agents against the oxidation of biomolecules. Even though our work has some limitations, we believe that it could be a starting point to future determine effective concentrations, possible levels of toxicity, and eventual secondary effects that can be generated by the use of these by-products. Based on our results, future work will focus on exploring the potential of molasses and vinasses as an antiproliferative agent in a cellular context. These new applications would not only contribute to the diversification of the sugarcane agroindustry but would also contribute to the reduction of the environmental and economic impacts that have traditionally been associated with the generation and final disposal of molasses and vinasses.

Acknowledgements The authors wish to thank to Ph.D. Andres Jaramillo-Botero and Ph.D. Nicolas Gil-Zapata for their support for developing this research. The authors were supported by the Colombian Administrative Department of Science, Technology and Innovation (Departamento Administrativo de Ciencia, Tecnología e Innovación-Colciencias).

Funding This work was supported by the Colombian Administrative Department of Science, Technology and Innovation (Departamento Administrativo de Ciencia, Tecnología e Innovación-Colciencias) through the Research Grant "Grant ID 808-Project ID: 125180864199".

\section{Compliance with Ethical Standards}

Conflict of interest The authors declare that they have no conflict of interest.
Open Access This article is distributed under the terms of the Creative Commons Attribution 4.0 International License (http://creativeco mmons.org/licenses/by/4.0/), which permits unrestricted use, distribution, and reproduction in any medium, provided you give appropriate credit to the original author(s) and the source, provide a link to the Creative Commons license, and indicate if changes were made.

\section{References}

1. United States Department of Agriculture (USDA): Sugar: World Markets and Trade. https://www.fas.usda.gov/data/sugar-world -markets-and-trade (2017). Accessed: 04 May 2018

2. Asociación de Cultivadores de Caña de Azúcar de Colombia (Asocaña): Aspectos generales del sector agroindustrial de la caña 2017-2018. Informe anual. Cali, Colombia (2018)

3. Centro de Investigación de la Caña de Azúcar de Colombia (Cenicaña): Proceso de obtención de azúcar. http://www.cenicana.org/ pop_up/fabrica/diagrama_obtencion.php (2004). Accessed 13 June 2017

4. Payet, B., Cheong Sing, A.S., Smadja, J.: Comparison of the concentrations of phenolic constituents in cane sugar manufacturing products with their antioxidant activities. J. Agric. Food Chem. 54, 7270-7276 (2006)

5. Mornadini, M., Quaia, E.: Alternativas para el aprovechamiento de la vinaza como subproducto de la actividad sucroalcoholera. Estación Experimental Agroindustrial Obispo Colombres. Tucumán, Argentina (2013)

6. Paturau, J.M.: Alternative uses of sugarcane and its byproducts in agroindustries. In: Sansoucy, R., Aarts, G., Preston, T.R. (eds.) Sugarcane as feed. La caña de azúcar como pienso. Food and Agriculture Organization of the United Nations (FAO), Rome (1986)

7. Sindhu, R., Gnansounou, E., Binod, P., Pandey, A.: Bioconversion of sugarcane crop residue for value added products - an overview. Renew. Energ. 98, 203-215 (2016)

8. Valli, V., Gómez-Caravaca, A.M., Di Nunzio, M., Danesi, F., Caboni, M.F., Bordoni, A.: Sugar cane and sugar beet molasses, antioxidant-rich alternatives to refined sugar. J. Agric. Food Chem. 60, 12508-12515 (2012)

9. Asikin, Y., Takahashi, M., Mishima, T., Mizu, M., Takara, K., Wada, K.: Antioxidant activity of sugarcane molasses against 2,2'-azobis(2-amidinopropane) dihydrochloride-induced peroxyl radicals. Food Chem. 141, 466-472 (2013)

10. Centro de Investigación de la Caña de Azúcar de Colombia (Cenicaña): Etanol: 10 años de producción en Colombia. Carta Informativa 4, 1-20 (2016)

11. Chuppa-Tostain, G., Hoarau, J., Watson, M., Adelard, L., Cheong Sing, A.S., Caro, Y., Grondin, I., Bourven, I., Francois, J.M., Girbal-Neuhauser, E., Petit, T.: Production of Aspergillus niger biomass on sugarcane distillery wastewater: physiological aspects and potential for biodiesel production. Fungal Biol. Biotechnol. 5, $1-12$ (2018)

12. Ahmed, O., Sulieman, A.M.E., Elhardallou, S.B.: Physicochemical, chemical and microbiological characteristics of vinasse, a byproduct from ethanol industry. Am. J. Biochem. 3, 80-83 (2013)

13. Rodrigues Reis, C.E., Hu, B.: Vinasse from sugarcane ethanol production: better treatment or better utilization? Front. Energy Res. 5, 1-7 (2017)

14. Kong, F., Yu, S., Zeng, F., Wu, X.: Preparation of antioxidant and evaluation of the antioxidant activities of antioxidants extracted from sugarcane product. J. Food Nutr. Res. 3, 458-463 (2015)

15. Guimarães, C.M., Gião, M.S., Martinez, S.S., Pintado, A.I., Pintado, M.E., Bento, L.S., Malcata, F.X.: Antioxidant activity of 
sugar molasses, including protective effect against DNA oxidative damage. J. Food Sci. 72, 39-43 (2007)

16. Baiano, A.: Recovery of biomolecules from food wastes-a review. Molecules 19, 14821-14842 (2014)

17. Payet, B., Cheong Sing, A.S., Smadja, J.: Assessment of antioxidant activity of cane brown sugars by ABTS and DPPH radical scavenging assays: determination of their polyphenolic and volatile constituents. J. Agric. Food Chem. 53, 10074-10079 (2005)

18. Duarte-Almeida, J.M., Salatino, A., Genovese, M.I., Lajolo, F.M.: Phenolic composition and antioxidant activity of culms and sugarcane (Saccharum officinarum L.) products. Food Chem. 125, 660-664 (2011)

19. Guan, Y., Tang, Q., Fu, X., Yu, S., Wu, S., Chen, M.: Preparation of antioxidants from sugarcane molasses. Food Chem. 152, 552-557 (2014)

20. Li, X., Yao, S., Tu, B., Li, X., Jia, C., Song, H.: Determination and comparison of flavonoids and anthocyanins in chinese sugarcane tips, stems, roots and leaves. J. Sep. Sci. 33, 1216-1223 (2010)

21. Li, X., Song, H., Yao, S., Jia, C., Yang, Y., Zhu, W.: Quantitative analysis and recovery optimisation of flavonoids and anthocyanins in sugar-making process of sugarcane industry. Food Chem. 125, 150-157 (2011)

22. Caderby, E., Baumberger, S., Hoareau, W., Fargues, C., Decloux, M., Maillard, M.N.: Sugar cane stillage: a potential source of natural antioxidants. J. Agric. Food Chem. 61, 11494-11501 (2013)

23. Seguí, L., Calabuig-Jiménez, L., Betoret, N., Fito, P.: Physicochemical and antioxidant properties of non-refined sugarcane alternatives to white sugar. Int. J. Food Sci. Technol. 50, 2579 2588 (2015)

24. Abbas, S.R., Sabir, S.M., Ahmad, S.D., Boligon, A.A., Athayde, M.L.: Phenolic profile, antioxidant potential and DNA damage protecting activity of sugarcane (Saccharum officinarum). Food Chem. 147, 10-16 (2014)

25. Liu, R.H.: Health benefits of fruit and vegetables are from additive and synergistic combinations of phytochemicals. Am. J. Clin. Nutr. 78, 3-6 (2003)

26. Liu, R.H.: Potential synergy of phytochemicals in cancer prevention: mechanism of action. J. Nutr. 134, 3479S-3485S (2004)

27. Lee, C.P., Chen, Z.T., Yu, P.Y., Wang, Y.C., Duh, P.D.: Identification of bioactive compounds and comparison of apoptosis induction of three varieties of sugarcane leaves. J. Funct. Foods. 4, 391-397 (2012)

28. Huang, W.Y., Cai, Y.Z., Zhang, Y.: Natural phenolic compounds from medicinal herbs and dietary plants: potential use for cancer prevention. Nutr. Cancer 62, 1-20 (2010)

29. Centro de Investigación de la Caña de Azúcar de Colombia (Cenicaña): Estandarización de los sistemas de medición en los ingenios azucareros de Colombia. Manual de Laboratorio-Volumen 1: Procedimientos analíticos. Cali, Colombia (1996)

30. Singleton, V.L., Orthofer, R., Lamuela-Raventós, R.M.: Analysis of total phenols and other oxidation substrates and antioxidants by means of Folin-Ciocalteu reagent. Method Enzymol. 299, 152-178 (1999)

31. Kim, D.O., Jeong, S.W., Lee, C.Y.: Antioxidant capacity of phenolic phytochemicals from various cultivars of plums. Food Chem. 81, 321-326 (2003)

32. Brand-Williams, W., Cuvelier, M.E., Berset, C.: Use of a free radical method to evaluate antioxidant activity. LWT-Food Sci. Technol. 28, 25-30 (1995)

33. Sonkawade, S.D., Naik, G.R.: In vitro evaluation of antioxidant properties of sugarcane extracts rich in dietary nucleotides. Int. J. Adv. Biol. Res. 5, 243-250 (2015)

34. Re, R., Pellegrini, N., Proteggente, A., Pannala, A., Yang, M., Rice-Evans, C.: Antioxidant activity applying an improved ABTS radical cation decolorization assay. Free Radic. Biol. Med. 26, 1231-1237 (1999)
35. Benzie, I.F.F., Strain, J.J.: The ferric reducing ability of plasma (FRAP) as a measure of 'antioxidant power': the FRAP assay. Anal. Biochem. 239, 70-76 (1996)

36. Benzie, I.F.F., Strain, J.J.: Ferric reducing/antioxidant power assay: direct measure of total antioxidant activity of biological fluids and modified version for simultaneous measurement of total antioxidant power and ascorbic acid concentration. Method Enzymol. 299, 15-27 (1999)

37. Pulido, R., Bravo, L., Saura-Calixto, F.: Antioxidant activity of dietary polyphenols as determined by a modified ferric reducing/ antioxidant power assay. J. Agric. Food Chem. 48, 3396-3402 (2000)

38. Nilima, S.R., Hande, S.M.: Estimation of phytochemical content and antioxidant activity of some selected traditional Indian medicinal plants. Indian J. Pharm. Sci. 73, 146-151 (2011)

39. Instituto Colombiano de Normas Técnicas y Certificación (ICONTEC): Norma Técnica Colombiana NTC 587-Industrias Alimentarias e Industrias de Bebidas. Melaza de Caña. Instituto Colombiano de Normas Técnicas y Certificación (ICONTEC) (1994)

40. Gasmalla, M.A.A., Yang, R., Nikoo, M., Man, S.: Production of ethanol from Sudanese sugar cane molasses and evaluation of its quality. J. Food. Process. Technol. 3, 1-4 (2012)

41. Aristizábal, C.E.: Caracterización físico-química de una vinaza resultante de la producción de alcohol de una industria licorera, a partir del aprovechamiento de la caña de azúcar. Revista de Ingenierías USBMED 6, 36-41 (2015)

42. Nelson, E.K.: Some organic acids of sugar cane molasses. J. Am. Chem. Soc. 51, 2808-2810 (1929)

43. Takara, K., Matsui, D., Wada, K., Ichiba, T., Nakasone, Y.: New antioxidative phenolic glycosides isolated from Kokuto non-centrifuged cane sugar. Biosci. Biotechnol. Biochem. 66, 29-35 (2002)

44. Jaffé, W.R.: Nutritional and functional components of non centrifugal cane sugar: a compilation of the data from the analytical literatura. J. Food Compos. Anal. 43, 194-202 (2015)

45. Duarte-Almeida, J.M., Negri, G., Salatino, A., de Carvalho, J.E., Lajolo, F.M.: Antiproliferative and antioxidant activities of a tricin acylated glycoside from sugarcane (Saccharum officinarum) juice. Phytochemistry 68, 1165-1171 (2007)

46. Manarim, G.R., De Aguilar, C.L.: Removal of pigments from sugarcane cells by adsorbent chromatographic column. Ann. Chromatogr. Sep. Tech. 2, 1-5 (2016)

47. Lutz, M., Hernández, J., Henríquez, C.: Phenolic content and antioxidant capacity in fresh and dry fruits and vegetables grown in Chile. CYTA J. Food. 13, 541-547 (2015)

48. Chandra, S., Khan, S., Avula, B., Lata, H., Yang, M.H., ElSohly, M.A., Khan, I.A.: Assessment of total phenolic and flavonoid content, antioxidant properties, and yield of aeroponically and conventionally grown leafy vegetables and fruit crops: a comparative study. Evid. Based Complement. Alternat. Med. (2014). https://doi.org/10.1155/2014/253875

49. Manohar, M.P., Harish Nayaka, A.M.: Mahadevaiah: studies on phenolic content and polyphenol oxidase activity of sugarcane varieties with reference to sugar processing. Sugar Tech. 16, 385-391 (2014)

50. Prior, R.L., Wu, X., Schaich, K.: Standardized methods for the determination of antioxidant capacity and phenolics in foods and dietary supplements. J. Agric. Food Chem. 53, 4290-4302 (2005)

51. Huang, D., Boxin, O., Prior, R.L.: The chemistry behind antioxidant capacity assays. J. Agric. Food Chem. 53, 1841-1856 (2005)

52. Alam, M.N., Bristi, N.J., Rafiquzzaman, Md: Review on in vivo and in vitro methods evaluation of antioxidant activity. Saudi Pharm. J. 21, 143-152 (2013) 
53. Lee, K.J., Oh, Y.C., Cho, W.K., Ma, J.Y.: Antioxidant and antiinflammatory activity determination of one hundred kinds of pure chemical compounds using offline and online screening HPLC assay. Evid. Based Complement. Alternat. Med 2015, 1-13 (2015)

54. Bunzel, M., Schenderl, R.R.: Determination of (total) phenolics and antioxidant capacity in food and ingredients. In: Nielsen, S.S. (ed.) Food Analysis, 5th edn, pp. 455-468. Springer, New York (2017)

55. Cerretani, L., Bendini, A.: Rapid assays to evaluate the antioxidant capacity of phenols in virgin olive oil. In: Preedy, V.R., Watson, R.R. (eds.) Olives and olive oil prevention, 1st edn, pp. 625-635. Elsevier, London (2010)

56. Duarte-Almeida, J.M., Vidal Novoa, A., Linares, A.F., Lajolo, F.M., Genovese, M.I.: Antioxidant activity of phenolics compounds from sugar cane (Saccharum officinarum L.) juice. Plant Food Hum. Nutr. 61, 187-192 (2006)

57. Balasundram, N., Sundram, K., Samman, S.: Phenolic compounds in plants and agri-industrial by-products: antioxidant activity, occurrence, and potential uses. Food Chem. 99, 191-203 (2006)

58. Del Rio, D., Rodriguez-Mateos, A., Spencer, J.P.E., Tognolini, M., Borges, G., Crozier, A.: Dietary (Poly)phenolics in human health: structures, bioavailability, and evidence of protective effects against chronic diseases. Antioxid. Redox Signal. 18, 1818-1892 (2013)

59. Bahadoran, Z., Mirmiran, P., Azizi, F.: Dietary polyphenols as potential nutraceuticals in management of diabetes: a review. J. Diabetes Metab. Disord. 25, 4454 (2013). https://doi. org/10.1186/2251-6581-12-43

60. Rasooli, I.: Bioactive compounds in phytomedicine. InTech, Rijeka (2011)

61. Cheung, P.C.K., Mehta, B.M.: Handbook of Food Chemistry. Springer, Heidelberg (2015)

62. Bendary, E., Francis, R.R., Ali, H.M.G., Sarwat, M.I., El Hady, S.: Antioxidant and structure-activity relationships (SARs) of some phenolic and anilines compounds. Ann. Agric. Sci. 58, 173-181 (2013)

\section{Affiliations}

\section{Andrea Molina-Cortés ${ }^{1,2}(\mathbb{D}) \cdot$ Tatiana Sánchez-Motta $^{3} \cdot$ Fabian Tobar-Tosse $^{2,4}\left(\mathbb{D} \cdot\right.$ Mauricio Quimbaya $^{2,5}$ (D)}

1 Universidad de San Buenaventura - Cali, Facultad de Ingeniería - Grupo de Investigación de Biotecnología, Carrera 122 \# 6-65, Cali, Valle del Cauca 760031, Colombia

2 Pontificia Universidad Javeriana Cali - Facultad de Ingeniería y Ciencias, Doctorado en Ingeniería, Calle 18 \# 118-250, Cali 760031, Valle del Cauca, Colombia

3 Centro de Investigación de la Caña de Azúcar de Colombia (Cenicaña) - Programa de Procesos de Fábrica, Estación Experimental vía Cali-Florida km 26, Florida, Valle del Cauca, Colombia
63. Zheng, R., Su, S., Zhou, H., Yan, H., Ye, J., Zhao, Z., You, L., $\mathrm{Fu}, \mathrm{X}$.: Antioxidant/antihyperglycemic activity of phenolics from sugarcane (Saccharum officinarum L.) bagasse and identification by UHPLC-HR-TOFMS. Ind. Crop. Prod. 101, 104-114 (2017)

64. Feng, S., Luo, Z., Zhang, Y., Zhong, Z., Lu, B.: Phytochemical contents and antioxidant capacities of different parts of two sugarcane (Saccharum officinarum L.) cultivars. Food Chem. 151, 452-458 (2014)

65. Echavarría, A.P., Pagán, J., Ibarz, A.: Melanoidins formed by Maillard reaction in food and their biological activity. Food Eng. Rev. 4, 203-223 (2012)

66. Asikin, Y., Kamiya, A., Mizu, M., Takara, K., Tamaki, H., Wada, $\mathrm{K}$. : Changes in the physicochemical characteristics, including flavour components and Maillard reaction products, of non-centrifugal cane brown sugar during storage. Food Chem. 149, 170-177 (2014)

67. Wang, H.Y., Qian, H., Yao, W.R.: Melanoidins produced by the Maillard reaction: structure and biological activity. Food Chem. 128, 573-584 (2011)

68. Langner, E., Rzeski, W.: Biological properties of melanoidins: a review. Int. J. Food Prop. 17, 344-353 (2014)

69. Kitts, D.D., Chen, X.M., Jing, H.: Demonstration of antioxidant and anti-inflammatory bioactivities from sugar-amino acid Maillard reaction products. J. Agric. Food Chem. 60, 6718-6727 (2012)

70. Carpenter, D.O., Arcaro, K., Spink, D.C.: Understanding the human health effects of chemical mixtures. Environ. Health Perspect. 110, 25-42 (2002)

Publisher's Note Springer Nature remains neutral with regard to jurisdictional claims in published maps and institutional affiliations.
$4 \quad$ Pontificia Universidad Javeriana Cali - Facultad de Ciencias de la Salud, Departamento de Ciencias Básicas de la Salud, Calle 18 \# 118-250, Cali 760031, Valle del Cauca, Colombia

5 Pontificia Universidad Javeriana Cali - Facultad de Ingeniería y Ciencias, Departamento de Ciencias Naturales y Matemáticas, Calle 18 \# 118-250, Cali 760031, Valle del Cauca, Colombia 